\title{
Associations Between Abortion-Records in Goats and Test-Positivity to Mycobacterium avium subsp. paratuberculosis
}

\author{
John Ikonomopoulos ${ }^{*}, 1$, Emmanouil Liandris ${ }^{1}$, Margarita Andreadou ${ }^{1}$ and Maria Gazouli ${ }^{2}$ \\ ${ }^{1}$ Agricultural University of Athens, Faculty of Animal Science, Laboratory of Anatomy-Physiology, 75 Iera Odos st., \\ 118.55, Athens, Greece \\ ${ }^{2}$ University of Athens, School of Medicine, Laboratory of Biology, 176 Michalakopoulou st., 11527 Athens, Greece
}

\begin{abstract}
Paratuberculosis, is a disease caused by Mycobacterium avium subsp. paratuberculosis (MAP) that affects mainly ruminants. MAP can disseminate from the intestine to the genital tract. Therefore infection has been associated with decreased fertility but not directly with abortion in goats. The aim of this study was to obtain the evidence required to exploit the potential association between MAP-infection and abortion. For this purpose we have focused on three caprine herds geographically unrelated and keeping records of paratuberculosis and abortion of unspecified etiology. We collected in total 178 serum, milk, and fecal samples from 63, 2-4 years old, female goats. This material was processed for cultivation, ELISA, and Real Time PCR (RT-PCR). No statistically significant association was recorded between abortionrecord and RT-PCR positivity to MAP of fecal or milk samples. However ELISA - positivity was linked at a statistically significant level $(\mathrm{p}=0.0275)$ with abortion. Goats that reacted positively by ELISA were 3.24 times more likely to abort than those with no detectable antibody titer. This study provides the first indications of the potential association of MAPinfection in goats and abortion-record, and suggests that a more extensive investigation should preferably rely on serology.
\end{abstract}

\section{INTRODUCTION}

Paratuberculosis, is a disease caused by Mycobacterium avium subsp. paratuberculosis (MAP) that affects mainly ruminants and causes severe economic loss that can be attributed to the reduced milk and meat production and the premature culling or death of the infected animals. MAP has been shown to disseminate from the intestine to the foetus, the embryonic membranes, and the cotyledons of infected bovines [1], as well as the udder and the uterus [2-5]. Therefore MAP-infection has been associated with decreased fertility that is however attributed to the negative energy balance caused by intestinal mal-absorption, rather than the direct impact of the pathogen on the genital tract [6]. The loss of nutrients and proteins reduces development and growth of corpora lutea that causes a decrease of serum progesterone [7,8], which can result to increased interval to first ovulation, reduced number of large follicles, and reduced growth of pre-ovulatory follicles [7,9]. Fertility is impaired even in animals with sub-clinical paratuberculosis for which the effect of mal-nutrition is less significant, something that has been demonstrated for bovines $[6,10,11]$, sheep and goats [12].

Abortion on the other hand is not considered a common feature of clinical paratuberculosis despite the fact that MAP has been isolated from the fetus, the placenta, the vagina, and the sperm $[3,5]$. Considering that the genital tract does not develop lesions during paratuberculosis, the failure of

*Address correspondence to this author at the Agricultural University of Athens, Faculty of Animal Science, Laboratory of Anatomy- Physiology, 75 Iera Odos st., 118.55, Athens, Greece; Tel: +30210594391;

Fax:+2105294388; E-mail: ikonomop@aua.gr
MAP to cause abortion may be associated with the so-called "goal-orientated nutrient partitioning", which secures adequate nutritional resources to the foetus even in animals with poor body condition.

However the immune imbalance caused by paratuberculosis might in theory trigger a reaction that could lead to abortion. This has been associated in bovines and guinea pigs with hypersensitivity reactions generated by Johnin testing or experimental exposure to MAP [13,14]. This effect may be more profound in goats than bovines and sheep, since they seem to develop a more damaging immune response to MAP with more defuse intestinal lesions and less chances of recovery [15]. To the best of our knowledge there are no reports investigating the association of paratuberculosis with abortion in goats. Therefore the aim of this study was to obtain the evidence required to exploit the potential association between MAP-infection and abortion-record. For this purpose we have focused on three herds of goats from different parts of the country and we collected fecal, serum, and milk samples that were processed for the isolation of MAP and the detection of MAP-antibody and DNA by cultivation, ELISA, and Real Time PCR (RT-PCR).

\section{MATERIALS AND METHODS}

\section{Sample Collection}

One hundred and seventy eight (178) samples were collected in total from 63 goats, from May to June 2007. This material consisted of serum $(n=63)$, feces $(n=63)$ and milk $(\mathrm{n}=52), 11$ animals were not lactating (dry period). The tested population belonged to 3 goat farms from Nomos Korinthias, Arkadias, and Prevezis, Greece, that were selected to have a record of paratuberculosis and abortions of unspecified etiology (Table 1). The animals of all the herds 
were reared semi-extensively sharing bedding, pasture, and breeding space. According to the regional veterinary authorities and the clinical examination of the animals at the time of sample collection, the manifestation of paratuberculosis in the herds was sub-acute with non-responsive intermittent diarrhea and weight-loss leading to death within a few months after first symptoms appeared. The record of abortions indicated that they were sporadic, more common in Spring, and corresponded approximately to $15-20 \%$ of the number of gestations per reproductive period. Of all the animals included in this study only one had aborted more than once, although it should be noted that the local farming practice imposes removal of animals from the herd if they have shown evidence of abortion or decreased fertility (revert to oestrus). Finally although there is practically no means to record accurately the date that an abortion occurs in a semiextensive goat farm, the evidence provided by the regional Veterinary Inspectors indicated that these were realized in all cases during the second or the final third of gestation.

Table 1. Sample Size and Abortion Record of the Tested Animals

\begin{tabular}{|c|c|c|c|c|}
\hline \multicolumn{5}{|c|}{ Number of Tested Animals per Herd } \\
\hline \multirow{2}{*}{ Herd Number } & \multirow{2}{*}{ Region (Nomos) } & \multicolumn{2}{|c|}{ Abortion Record } & \multirow{2}{*}{ Total } \\
\cline { 3 - 4 } & & Yes & No & \\
\hline \hline 1 & Korinthias & 8 & 18 & 26 \\
\hline 2 & Arkadias & 3 & 15 & 18 \\
\hline 3 & Prevezis & 2 & 17 & 19 \\
\hline & Total & 13 & 50 & 63 \\
\hline
\end{tabular}

The samples were collected from female goats from 2 to 4 years of age that were selected randomly by ballot draw. The size of the tested population was estimated to correspond to no less than $25 \%$ of the animals of the same sex and age per herd at the time of sampling. This percentage that was defined empirically in the absence of relevant publications was expected to secure adequate level of MAPexposure of the tested population, since the relevant percentage in bovine farms with paratuberculosis has been estimated to more than $47 \%$ [16].

A questionnaire about the disease record of each animal was completed on the spot (Table 1). Based on the latter and the clinical examination of the animals at the time of sample collection, two of the tested goats were recognized with symptoms suggestive of paratuberculosis.

The samples were marked with coded numbers and were stored immediately in refrigerated containers until transportation to the laboratory that was completed within 4-6 hours after the collection of the material. The serum samples were used for the detection of MAP and Brucella-specific antibody by ELISA, while milk and feces were processed for isolation and detection of MAP- DNA by cultivation and RT-PCR, respectively.

\section{DNA Isolation}

DNA isolation from feces was performed with the $\mathrm{Nu}$ cleospin tissue kit (Macherey Nagel, Düren, Germany).
Briefly, $2 \mathrm{~g}$ of feces were homogenized with $20 \mathrm{ml}$ of sterile water for $5 \mathrm{~min}$. After $20 \mathrm{~min}$ of sedimentation at room temperature, $600 \mu \mathrm{l}$ of the supernatant were transferred to a 1.5 $\mathrm{ml}$ tube containing $300 \mathrm{mg}$ glass beads (Adiagene, Montpellier, France) and they were disrupted in a Mixer Mill (Retsch, Haan, Germany) at $30 \mathrm{~Hz}$ for $10 \mathrm{~min}$. The liquid phase was collected and incubated overnight with $30 \mu \mathrm{l}$ of proteinase $\mathrm{K}(20 \mathrm{mg} / \mathrm{ml})$ and then processed with the $\mathrm{Nu}$ cleospin Tissue kit (Macherey Nagel, Düren, Germany) according to the instructions of the manufacturer.

For DNA isolation from milk, samples of $50 \mathrm{ml}$ were processed with the Adiapure PARATB milk DNA extraction and purification kit (ADIAGENE, Saint Brieuc, France), according to the instructions of the manufacturer.

Evaluation of the quality of the DNA extract with reference to quantity, purity, and integrity was performed with optical density (OD) counts and agarose gel electrophoresis as previously described [17]. In order to assess the presence of PCR inhibitors in our DNA preparations, all the samples were subjected to a PCR assay, amplifying a 900 bp DNA fragment of an in-house gene (cytochrome c) of goats (data not shown). DNA preparations of poor quality or those that failed to produce the expected product with the PCR assay mentioned above were discarded, and DNA isolation was repeated from the original sample.

\section{Detection of MAP-DNA by RT-PCR}

Detection of MAP DNA was performed on the fecal $(\mathrm{n}=$ $63)$ and milk $(n=52)$ samples collected from the tested animals by a RT-PCR that consisted a modification of the one originally described by Kim et al. [18]. In more detail, each reaction was prepared to a final volume of $20 \mu$ containing 5 $\mu$ of DNA sample and $1 \mathrm{X}$ of LightCycler TaqMan Master (Roche, Mannheim, Germany), $0.5 \mu \mathrm{M}$ of each of the two primers (5'-AAT GAC GGT TAC GGA GGT GGT-3', and 5'-GCA GTA ATG GTC GGC CTT ACC-3', Thermo Scientific, Germany), and $0.25 \mu \mathrm{M}$ of the internal probe (tqMAP: 6FAMTCCACGCCCGCCCAGACAGGTAMRA, Applied Biosystems, Foster City, USA) that was labeled with the fluorescent reporter dye 6-carboxyfluorescein on the 5' end, and the quencher dye N', N', N', N' - tetramethyl-6carboxyrhodamine on the 3 ' end. Amplification was performed in a LightCycler 2 (Roche, Basel, Switzerland) at $95^{\circ} \mathrm{C}$ for 10 minutes followed by 45 cycles of $95^{\circ} \mathrm{C}$ for 10 sec, $60^{\circ} \mathrm{C}$ for $1 \mathrm{~min}$, and $72^{\circ} \mathrm{C}$ for $2 \mathrm{sec}$. Positive and negative controls incorporated in each assay corresponded approximately to $10 \%$ of the samples tested per batch and consisted respectively of the reaction mixture containing MAP DNA (positive control) and total DNA of confirmed PCRnegative fecal samples or water (negative control).

\section{Cultivation for the Isolation of MAP}

Cultivation was performed on the milk $(\mathrm{n}=52)$ and fecal $(\mathrm{n}=63)$ samples as previously described $[19,20]$. In brief, after homogenization, decontamination of each sample was performed on $2 \mathrm{gr}$ of feces and $50 \mathrm{ml}$ of milk, with $0.9 \%$ hexa-decyl-pyridinium chloride (HPC, Sigma Aldrich, Germany) in brain heart infusion (BHI) broth (final concentration $0.75 \% \mathrm{HPC}$ ) at $37^{\circ} \mathrm{C}$ for 24 and 5 hours respectively. The sediment (feces) and the supernatant (milk) was incubated again in BHI (Oxoid, Hampshire, UK) with $100 \mu \mathrm{g}$ of 
vancomycin, $100 \mu \mathrm{g}$ of nalidixic acid, and $50 \mu \mathrm{g}$ amphotericin $\mathrm{B}$ at $37^{\circ} \mathrm{C}$ for 24 hours [21]. All antimicrobial agents were supplied by Sigma St. Louis, USA. After neutralization, this material was inoculated onto four growth media per sample i.e. Herrold's Egg Yolk Medium (Becton Dickinson, USA) and Lowenstein-Jensen (Pourqier Institute, France) that were also used modified with the addition of $2 \mathrm{mg} / \mathrm{L}$ of Mycobactin J (Pourqier Institute, France). These media were incubated aerobically and microaerophilically (duplicate cultures) at $37^{\circ} \mathrm{C}$ for up to 10 months.

\section{Detection of MAP and Brucella-Specific Antibodies by ELISA}

ELISA was performed on our serum samples $(n=63)$. Detection of MAP and Brucella-specific antibodies was performed respectively by the Pourquier (POURQUIER ${ }^{\circledR}$ ELISA PARATUBERCULOSIS ANTIBODY SCREENING -Institut Pourquier, France) and the Svanovir (SVANOVIR $^{\mathrm{TM}}$ Brucella-Ab c-ELISA-Svanova Biotech AB Uppsala, Sweden) ELISA kits, according to the instructions of the manufacturers.

\section{Statistics}

The association between test-positivity to MAP and abortion-record was assessed by contingency table analysis using the Fisher's exact test because of sparse cells in the table(s). During this analysis the relative risk(s) (with 95\% confidence intervals) was also calculated on the assumption of equal follow up per subject (Table 4). All the above analyses were carried out with the Graphpad Instat software, version 3.05 (Graphpad software Inc., California).

\section{RESULTS}

Twenty two (22) of the 63 fecal samples (34.9\%), and 10 of the 52 milk samples $(19.2 \%)$ produced positive results by RTPCR. From the 63 fecal and 52 milk samples that were cultivated for the isolation of MAP, positive results were recorded from 4 fecal and 3 milk samples (6.3\% and 5.8\% respectively), that were collected from 4 of the tested goats. These samples had also reacted positively by RT-PCR (Table 2 ).

Table 2. The Results Recorded on the Tested Milk, Fecal, and Serum Samples by RT-PCR, ELISA, and Culture

\begin{tabular}{|c|c|c|c|c|c|c|c|c|c|}
\hline \multirow{2}{*}{\multicolumn{2}{|c|}{ Sample }} & \multirow{2}{*}{\multicolumn{2}{|c|}{ RT-PCR }} & \multicolumn{4}{|c|}{ ELISA } & \multirow{2}{*}{\multicolumn{2}{|c|}{ Culture }} \\
\hline & & & & \multicolumn{2}{|c|}{ MAP } & \multicolumn{2}{|c|}{ BRUCELLA } & & \\
\hline Type & Size & + & - & + & - & + & - & + & - \\
\hline Milk & 52 & 10 & 42 & & & & & 3 & 49 \\
\hline Feces & 63 & 22 & 41 & & & & & 4 & 59 \\
\hline Serum & 63 & & & 25 & 36 & 0 & 63 & & \\
\hline
\end{tabular}

ELISA testing of the 63 serum samples for the detection of MAP-specific antibody produced $25(39.7 \%)$ positive, and 2 $(3.2 \%)$ dubious results. In order to increase the reliability of our assessment the dubious results were not included in our evaluation. Finally, none of the tested samples produced positive result for the detection of Brucella antibody (Table 2).

Thirty (30) of the $63(47.6 \%)$ tested animals reacted positively to at least one of the diagnostic tests incorporated in this study (ELISA performed on serum, RT-PCR performed on milk and fecal samples, cultivation of feces and milk), 16 $(53.4 \%)$ produced positive results in two of these tests and only 3 goats reacted positively to all the tests incorporated in this study for the detection of MAP. Two of these were diagnosed with active paratuberculosis at the time of sample collection.

Twelve of the $18(66.7 \%)$ animals from which RT-PCR performed on feces produced positive results, reacted positively by ELISA. Twelve (12) of the 22 (54.5\%) goats that produced positive results by the latter method produced fecal samples that allowed detection of MAP DNA by RT-PCR. Half of the $10(50 \%)$ animals that produced RT-PCR positive milk samples were also characterised positive by serology, whereas 5 of the $16(31.25 \%)$ ELISA-positive animals were also positive to RT-PCR performed on milk (Table 3). Seven (7) of the $10(70 \%)$ animals with RT-PCR positive milk samples, produced feces that reacted positively by the same test. Finally, of the 30 animals that produced milk or fecal RT-PCR positive samples, 16 were characterized positive by ELISA $(53.3 \%)$, whereas the relevant percentage for RT-PCR and cultivation was $13.3 \%$ (4 culture-positive of the 30 RT-PCR positive animals).

Table 3. Correlation of the Results Recorded by RT-PCR and ELISA

\begin{tabular}{|c|c|c|c|c|c|}
\hline \multirow{2}{*}{\multicolumn{2}{|c|}{}} & \multicolumn{4}{|c|}{ RT-PCR Performed on } \\
\cline { 3 - 6 } \multicolumn{2}{|c|}{} & \multicolumn{2}{|c|}{ Feces } & \multicolumn{2}{c|}{ Milk } \\
\cline { 3 - 6 } \multicolumn{2}{|c|}{} & + & - & + & - \\
\hline \hline \multirow{2}{*}{ ELISA } & + & 15 & 10 & 5 & 11 \\
\cline { 2 - 6 } & - & 6 & 30 & 5 & 29 \\
\hline & Total & $\mathbf{2 1}$ & & $\mathbf{1 0}$ & \\
\hline
\end{tabular}

Based on the evaluation of our results by the Fisher's exact test, no statistically significant association was recorded between abortion and RT-PCR positivity to MAP of fecal $(p=0.76)$ or milk $(p=1)$ samples. However positivity for the detection of MAP-specific antibody by ELISA was linked at a statistically significant level $(\mathrm{p}=0.0275)$ with abortion. Goats that reacted positively by the latter test were 3.24 times more likely to abort than those with no detectable antibody titer (relative risk $=3.24 ; 95 \%$ confidence interval 1.121-9.37) (Table 4).

Table 4. Correlation of Abortion with the Results Obtained by RT-PCR and ELISA on the Tested Fecal, Milk, and Serum Samples

\begin{tabular}{|c|c|c|c|c|c|c|}
\hline \multirow{2}{*}{ Abortion } & \multicolumn{4}{|c|}{ RT-PCR } & \multicolumn{2}{c|}{ ELISA } \\
\cline { 2 - 7 } & \multicolumn{2}{|c|}{ Feces } & \multicolumn{2}{c|}{ Milk } & \multicolumn{2}{c|}{ for MAP } \\
\cline { 2 - 7 } & + & - & + & - & + & - \\
\hline \hline Yes & 5 & 8 & 1 & 9 & 9 & 4 \\
\hline No & 17 & 33 & 6 & 36 & 16 & 32 \\
\hline & \multicolumn{2}{|c|}{$\mathbf{p}=\mathbf{0 . 7 6}$} & \multicolumn{2}{|c|}{$\mathbf{p = 1}$} & \multicolumn{2}{c|}{$\mathbf{p = 0 . 0 2 7 5}$} \\
\hline
\end{tabular}




\section{DISCUSSION}

In this study we have incorporated all the types of tests commonly applied for the diagnostic investigation of paratuberculosis in order to assess which method and clinical material can be used to investigate if an association can be established between MAP-positivity and abortion record. Given that it was not our purpose to investigate the pathogenesis of abortions possibly attributed to the specific pathogen but to provide markers that could be used for a larger scale association study, the clinical material that was collected from the targeted population were selected among those routinely used for the monitoring of paratuberculosis in ruminants.

A very considerable issue that has to be resolved in association studies is case definition. This becomes more problematic for paratuberculosis since positivity of the tests incorporated to the diagnosis of the disease and especially the results of cultivation can vary upon several factors such as clinical stage, animal species, parity, stage of lactation, sample decontamination $[19,22]$. The impact of the latter on the ability to isolate low viability strains and the intermittent fecal excretion of MAP by carrier animals is usually considered the source of the inconsistency that is often observed with connection to the positive results recorded by cultivation and molecular detection of MAP or ELISA. This is reflected in our findings too, with cultivation producing positive results after 10 months of incubation from only 7 of the samples that allowed detection of MAP by RT-PCR. Effectively the level of positivity per animal between RT-PCR and ELISA proved two times higher than that between RTPCR and cultivation. The relative consistency between ELISA and RT-PCR may be associated with constrains resulting from the selection of the targeted population since in order to minimize false positive results, we excluded herds of animals exposed to mycobacteria through vaccination, johnin or tuberculin testing. Furthermore, in order to decrease the bias introduced to our results by factors that could lead to abortion not related to MAP-infection, the animals included in this study were selected from three sites that were distant to each other (different geographic parts of the country, no direct or indirect contact). Finally the tested population was also evaluated for the presence of Brucellaspecific antibody, since brucellosis consists according to the records of the Greek Ministry of Agriculture, a common cause of sporadic abortion in small ruminant in the country (not published).

In this study, positivity of culture or RT-PCR of fecal and milk samples was not associated with abortion-record. The results however recorded by ELISA on the serum samples collected from the tested population provide an indication that in goats, MAP-infection maybe associated with abortion $(p=0.0275)$. Obviously our findings do not prove a functional significance among the two parameters associated, since MAP-seropositivity may consist just a marker for abortion in goats. If however a functional role were hypothesized, it would have to be attributed either to the direct effect of MAP on the genital tract, which however is not consistent with the fact that infection by the specific pathogen does not generate lesions in the area, or to a generalized immune imbalance triggered in goats after infection. The potential significance of the immune reaction triggered by the specific pathogen to the pathogenesis of abortion is probably indi- cated by the fact that a positive association was recorded with connection to the presence of MAP-specific antibody in the blood but not RT-PCR positivity of the feces or the milk. This hypothesis is not inconsistent with the pathogenesis of paratuberculosis since it has been documented that the increase in the MAP-specific antibody titer is associated with the dissemination of the infection and the migration of MAP through the macrophages to other organs such as the uterus and the ovaries $[3,5]$.

In conclusion it can be stated that this study provides the first indications on the potential association of MAPinfection in goats and abortion-record and suggests that a more extensive investigation should preferably rely on serology, rather than RT-PCR and cultivation of feces or milk.

\section{REFERENCES}

[1] Doyle TM. Foetal infection in Johne's disease. Vet Rec 1958; 70: 328.

[2] Merkal RS. Paratuberculosis: advances in cultural, serologic and vaccination methods. J Am Vet Med Assoc 1984; 184: 939-43.

[3] Seitz SE, Heider LE, Hueston WD, et al. Bovine fetal infection with Mycobacterium paratuberculosis. J Am Vet Med Assoc 1989; 194: $1423-6$

[4] Lugton I. Mucosa-associated lymphoid tissues as sites for uptake, carriage and excretion of tubercle bacilli and other pathogenic mycobacteria. Immunol Cell Biol 1999; 77: 364-72.

[5] Sweeney RW, Whitlock RH, Rosenberger AE. Mycobacterium paratuberculosis isolated from the fetuses of infected cows not manifesting signs of the disease. Am J Vet Res 1992; 53: 477-80.

[6] Johnson-Ifearulundua YJ, Kaneenea JB, Sprecherb DJ, Gardinerc JC, Lloydd JW. The effect of subclinical Mycobacterium paratuberculosis infection on days open in Michigan, USA, dairy cows. Prev Vet Med 2000; 46: 171-81.

[7] Terhune AF. The association of preovulatory follicular events with morphology and progesterone of corporea lutea in heifers fed high or low energy diets. M.S. Thesis. Michigan State University: Michigan, 1993; pp. 1-20, 57-62.

[8] Van DeHaar MJ, Sharma BK, Fogwell RL. Effect of dietary energy restriction on the expression of insulin-like growth factor-I in liver and corpus luteum of heifers. J Dairy Sci 1995; 78: 832-41.

[9] Britt JH. Follicular development and fertility: potential impacts of negative energy balance. In proceedings of the 1994 Reproduction Symposium, Pittsburgh, PA, 1994; pp. 103-12.

[10] Merkal RS, Larsen AB, Booth GD. Analysis of the effect of inapparent bovine paratuberculosis. Am J Vet Res 1975; 36: 837-8.

[11] Buergelt CD, Duncal JR. Age and milk production data of cattle culled from a dairy herd with paratuberculosis. J Am Vet Med Assoc 1978; 173: 478-480.

[12] Kostoulas P, Leontides L, Billinis C, Amiridis GC, Florou M. The association of sub-clinical paratuberculosis with the fertility of Greek dairy ewes and goats varies with parity. Prev Vet Med 2006; 74: 226-38.

[13] Merkal RS, Miller GM, Hintz AM, Bryner JH. Intrauterine inoculation of Mycobacterium paratuberculosis into guinea pigs and cattle. Am J Vet Res 1981; 43: 676-8.

[14] Ayele WY, Bartos M, Svastova P, Pavlik I. Distribution of Mycobacterium avium subsp. paratuberculosis in organs of naturally infected bull-calves and breeding bulls. Vet Microbiol 2004; 103: 209-17.

[15] Corpa JM, Garrido J, Garcia Marin JF, Perez V. Classification of lesions observed in natural cases of paratuberculosis in goats. J Comp Pathol 2000; 122: 255-6.

[16] Kudahl AB, Ostergaard S, Sorensen JT, Nielsen SS. A stochastic model simulating paratuberculosis in a dairy herd. Prev Vet Med 2007; 78: 97-117.

[17] Ikonomopoulos J, Gorgoulis VG, Zacharatos PV, et al. Multiplex polymerase chain reaction for the detection of mycobacterial DNA in cases of tuberculosis and sarcoidosis. Mod Pathol 1999; 12: 85462 .

[18] Kim SG, Kim EH, Lafferty CJ, et al. Use of conventional and realtime polymerase chain reaction for confirmation of Mycobacterium 
avium subsp. paratuberculosis in a broth-based culture system ESP II. J Vet Diagn Invest 2004; 16: 448-53.

[19] Whipple DL, Callihan DR, Jarnagin JL. Cultivation of Mycobacterium paratuberculosis from bovine fecal specimens and a suggested standardized procedure. J Vet Diagn Invest 1991; 3: 368-73.

[20] Dundee L, Grant IR, Ball HJ, Rowe MT. Comparative evaluation of four decontamination protocols for the isolation of Mycobacterium avium subsp. paratuberculosis from milk. Lett Appl Microbiol 2001; 33: 173-7.
[21] Reddacliff LA, Vadali A, Whittington RJ. The effect of decontamination protocols on the numbers of sheep strain Mycobacterium avium subsp. paratuberculosis isolated from tissues and faeces. Vet Microbiol 2003; 95: 271-82.

[22] Nielsen SS, Grohn YT, Enevoldsen C. Variation of the milk antibody response to paratuberculosis in naturally infected cows. J Dairy Sci 2002; 85: 2795-802.

Received: October 24, 2008

Revised: November 19, 2008

Accepted: December 1, 2008

(C) Ikonomopoulos et al.; Licensee Bentham Open.

This is an open access article licensed under the terms of the Creative Commons Attribution Non-Commercial License (http://creativecommons.org/licenses/by$\mathrm{nc} / 3.0 /$ ) which permits unrestricted, non-commercial use, distribution and reproduction in any medium, provided the work is properly cited. 